\title{
LUT
}

University

\section{Controlled partial neutralization of amphoteric ion exchange resin for} improved metals separation

\author{
Virolainen Sami, Suppula Ilkka, Sainio Tuomo
}

This is a Final draft

version of a publication

published by Elsevier

in Reactive and Functional Polymers

DOI: $10.1016 /$ j.reactfunctpolym.2013.01.013

Copyright of the original publication: (c) 2013 Elsevier Ltd.

Please cite the publication as follows:

Virolainen, S., Suppula, I., Sainio, T., 2013. Controlled partial neutralization of amphoteric ion exchange resin for improved metals separation. Reactive and Functional Polymers 73, 647-652. doi:10.1016/j.reactfunctpolym.2013.01.013

This is a parallel published version of an original publication. This version can differ from the original published article. 


\section{Accepted Manuscript}

Controlled Partial Neutralization of Amphoteric Ion Exchange Resin for Improved Metals Separation

Sami Virolainen, Ilkka Suppula, Tuomo Sainio

PII:

S1381-5148(13)00025-4

DOI: http://dx.doi.org/10.1016/j.reactfunctpolym.2013.01.013

Reference: REACT 3174

To appear in:

Reactive \& Functional Polymers

REACTIVE \& FUNCTIONAL POLYMERS

Received Date: $\quad 19$ November 2012

Revised Date: 17 January 2013

Accepted Date: $\quad 22$ January 2013

Please cite this article as: S. Virolainen, I. Suppula, T. Sainio, Controlled Partial Neutralization of Amphoteric Ion Exchange Resin for Improved Metals Separation, Reactive \& Functional Polymers (2013), doi: http://dx.doi.org/ 10.1016/j.reactfunctpolym.2013.01.013

This is a PDF file of an unedited manuscript that has been accepted for publication. As a service to our customers we are providing this early version of the manuscript. The manuscript will undergo copyediting, typesetting, and review of the resulting proof before it is published in its final form. Please note that during the production process errors may be discovered which could affect the content, and all legal disclaimers that apply to the journal pertain. 
Revised (28.12.2012) version of:

\title{
Controlled Partial Neutralization of Amphoteric Ion Exchange Resin for Improved Metals Separation
}

\author{
Submitted by \\ Sami Virolainen, Ilkka Suppula, and Tuomo Sainio ${ }^{*}$ \\ from Lappeenranta University of Technology, Laboratory of Industrial \\ Chemistry, P.O. Box 20, FI-53851 Lappeenranta, Finland \\ to Reactive and Functional Polymers \\ on November 19, 2012 and revised on January 17, 2013
}

*) Corresponding author.Tel.: +358 40 3578683; e-mail address: tuomo.sainio@lut.fi 
1 Abstract

2

Controlled partial neutralization of an amphoteric aminomethylphosphonium functional ion exchange resin (Lewatit TP-260) was investigated. The particular goal of controlled neutralization was to replace $\mathrm{H}^{+}$in the acidic phosphonium groups with $\mathrm{Na}^{+}$ ions but leave the basic amino groups protonated. In this manner, metals' sorption is enhanced and undesired $\mathrm{pH}$ changes during the metal separation process are avoided. The conjugate bases of organic weak acids (sodium formiate, sodium acetate and sodium citrate), sodium phosphate and $\mathrm{NaOH}$ were studied as neutralizing agents. The organic acid salts and sodium phosphate were all found to be suitable. Lengthening the neutralization cycle and using more concentrated neutralization agents were found to yield higher extents of neutralization and more uniform profiles along a resin bed. Concentrated $\mathrm{NaOH}$ also neutralized the amine group from the resin. With dilute $\mathrm{NaOH}$, desired extent of neutralization was not achieved within a reasonable time. The effect of partial neutralization on metal sorption was tested with dynamic single column experiments. 5.5 $\mathrm{BV}$ of $\mathrm{Ag}-\mathrm{NaCl}$ solution could be purified from $\mathrm{Ca}, \mathrm{Mg}, \mathrm{Pb}$ and $\mathrm{Zn}$ when the resin was partially neutralized with $2.0 \mathrm{M} \mathrm{NaAc}$. With the acid form resin, the impurity metals broke through at $1.0 \mathrm{BV}$.

Keywords: amphoteric resin, chelating resin, aminomethylphosphonium, silver chloride, sodium acetate

Introduction

Chelating ion exchangers are known to be effective adsorbents for base metals and heavy metals in the form of divalent cations [1,2]. Consequently, they have potential for purification of hydrometallurgical solutions of many rare and valuable metals, which are often in form of complexes, oxoanions, monovalent cations, etc.

When working with solutions having $\mathrm{pH}$ near the neutral range and with ion exchangers that have functional groups with both acid and base properties, it is important to modify the functional groups to the desired form before the actual adsorption stage. This 
step is required because functional groups may bind or release $\mathrm{H}^{+}$ions and cause $\mathrm{pH}$ changes in the column. Such changes may lead to decreased metal sorption, if the $\mathrm{pH}$ decreases, or precipitation problems, if it increases.

A usual pretreatment or regeneration of amphoteric resins is to totally convert the resin either into acid or base form by using a concentrated acid or base. An iminodiacetate resin, for example, is usually regenerated with concentrated acid to remove bound metals. Maximal dynamic metal binding capacity is obtained by subsequently neutralizing the resin with a strong base. The drawback is that the amine group becomes converted to the free base form and will capture $\mathrm{H}^{+}$ions from the solution to be purified, increasing its $\mathrm{pH}$ and causing a risk of precipitation. A method is needed to neutralize in a controlled manner only the carboxylic groups while leaving the amine group protonated.

Although weak acids or bases have been used in regeneration instead of strong acids and bases, controlled partial neutralization of ion exchange resins has not been studied systematically in the available literature. For example, $\mathrm{CO}_{2}$ regeneration has been proposed for weak acid resins by Kiehling and Hoell [3], Kunin and Vasillou [4] and Larsen [5], and the resulting $\mathrm{HCO}_{3}{ }^{-}$solutions were used for regenerating weak base resins. Greenleaf and Sengupta [6] have used $\mathrm{CO}_{2}$ (in rainwater or snowmelt) regeneration for ion exchange fibers with weak acid functionality as a part of a water softening process. Bayard et al. [7] describe a procedure for preparing a packed bed of an iminodiacetic acid resin where part of the resin particles are completely in acid form and part in half neutralized form. $20 \%$ of the resin volume is moved into a separate column where it is treated with $2 \mathrm{~N} \mathrm{HCl}$ followed by water elution to $\mathrm{pH} 4.5$. This fraction is then mixed with particles that have previously been converted to monosodium iminodiacetate form (most probably by titration). Such a complicated procedure is hardly suitable for high throughput industrial processes.

A different approach to eliminate $\mathrm{pH}$ variations was employed by Trochimczuk et al. $[8,9]$, who used an acetate buffer in the feed when studying adsorption of metals into chelating resins that were used in $\mathrm{H}^{+}$form. This method introduces an additional chemical to the target metal solution, which may be undesirable. Moreover, sorption of metals by the resin is greatly reduced if they form complexes with the organic acids in the solution phase.

Citrate, tartrate and complexing agents in general (e.g. EDTA) have been used to improve stripping of metals from ion exchange resins. They also have a strong tendency to capture species that they have affinity to associate with, such as $\mathrm{H}^{+}$ions, from resins [10]. 
If partial neutralization is needed in a dynamic column operation, it is important to have as even a neutralization profile along the column as possible to ensure good performance. For example, if a stoichiometric amount of a strong acid or a strong base is used for partial neutralization of a bed, the extent of neutralization averaged over the column length may be appropriate, but there may be a steep gradient in the concentration of protonated functional groups near the column inlet.

The purpose of this work was to find suitable chemicals and conditions for controlled partial neutralization of an amphoteric aminomethylphosphonium resin in order to prevent precipitations while maintaining good removal capacity for impurity metals in dynamic column operation. The conjugate bases of organic weak acids (sodium formiate NaFo, sodium acetate $\mathrm{NaAc}$, and sodium citrate $\left.\mathrm{Na}{ }_{3} \mathrm{Ci}\right)$, sodium phosphate $\left(\mathrm{Na}_{2} \mathrm{HPO}_{3}\right)$ and $\mathrm{NaOH}$ were studied as neutralizing agents. The influence of partial neutralization on metals' sorption was tested in a single column for purification of $\mathrm{Ag}(\mathrm{I})$ from divalent impurity metals in concentrated chloride medium. Process performance was evaluated based on the volume of purified $\mathrm{AgCl}$ solution obtained before the breakthrough of the impurity metals. Only a single flow rate was used and the influence of extent of neutralization on mass transfer rates was thus not investigated in detail.

\section{Experimental}

\subsection{Materials}

All the chemicals used were of analytical grade, except $\mathrm{NaCl}$, which was of technical grade. The chemicals were supplied by VWR Prolabo ( $\mathrm{NaCl}, \mathrm{AgCl}$, citric acid $\left.\mathrm{H}_{3} \mathrm{Ci}\right)$, Alfa Aesar $\left(\mathrm{PbCl}_{2}\right)$, Merck $\left(\mathrm{ZnCl}_{2}\right.$, acetic acid $\mathrm{HAc}, \mathrm{HCl}$, formic acid $\left.\mathrm{HFo}, \mathrm{NaOH}\right)$, Riedel de Haën $\left(\mathrm{MgCl}_{2} \cdot 6 \mathrm{H}_{2} \mathrm{O}, \mathrm{Na}_{2} \mathrm{HPO}_{4}\right)$ and J.T. Baker $\left(\mathrm{CaCl}_{2} \cdot 2 \mathrm{H}_{2} 0\right)$.

Lewatit TP-260 (supplied by Lanxess) is a macroporous aminomethylphosphonic acid -functional resin that has a crosslinked polystyrene divinylbenzene matrix (Fig. 1) [11]. Physical properties given by manufacturer [11] of the resin are following: total capacity $2.3 \mathrm{eq} / \mathrm{L}$, particle size $0.4-1.25 \mathrm{~mm}$ ( $>90 \%$ ), water retention $58-62 \%$, volume change from $\mathrm{Na}^{+}$to $\mathrm{H}^{+}$form max. $25 \%$. The density of the resin was determined as 1.19 $\mathrm{g} / \mathrm{mL}$ in $4.8 \mathrm{M} \mathrm{NaCl}$ in this work. Before the experiments the resin was subjected to two 
four-stage pretreatment cycles where 10 to 20 bed volumes of $1 \mathrm{M} \mathrm{NaOH}$, water, $1 \mathrm{M} \mathrm{HCl}$, and water were passed through a resin bed.

\subsection{Titration of resin}

$<<$ Figure 1 about here $>>$

Titrations of the Lewatit TP-260 resin with and without $\mathrm{NaCl}$ background were done batchwise in test tubes. Wet free base form resin, $0.5 \mathrm{M} \mathrm{NaOH}, 1 \mathrm{M} \mathrm{HCl}$ and purified water were weighed into the test tube. The total liquid volume was $10 \mathrm{~mL}$. Test tubes were shaken for two days at $50^{\circ} \mathrm{C}$ and solution $\mathrm{pH}$ was measured after separation of the phases. Calibration curves were constructed to both acidic and base side to convert the $\mathrm{pH}$ readings to $\mathrm{H}^{+}$and $\mathrm{OH}^{-}$concentrations.

\subsection{Neutralization and separation experiments}

Neutralization of the resin and removal of divalent impurity metals from an $\operatorname{Ag}(\mathrm{I})$ solution were investigated in laboratory scale columns. The experiments were done at 50 ${ }^{\circ} \mathrm{C}$ in $15 \mathrm{~mm}$ diameter columns (Kronlab ECO15/120M3K-K) with a 24.0-27.6 mL resin bed. All feed solutions were placed on scales to monitor flow rates. Air was removed from the solutions with a vacuum pump before experiments and the solutions were passed through a degassing unit (Phenomenex Degassex DG-4400) before the column to remove traces of dissolved gases.

Partial neutralization of the resin was carried out in five consecutive steps as described in Table 1. The procedure was otherwise identical in all runs but the neutralization solution in step 3 was varied. A high salt concentration was used in all steps to maintain the ionic strength, and thus the extent of resin swelling, at approximately the same level as in the Ag solution to be purified. After the final rinse with $\mathrm{H}_{2} \mathrm{O}$, the resin bed was divided into five or six sections of approximately equal height that were removed from the column and titrated with $\mathrm{NaOH}$ to determine the $\mathrm{H}^{+}$content. The $\mathrm{H}^{+}$content was then compared to the $\mathrm{H}^{+}$content of completely protonated resin to calculate the extent of neutralization. 
The influence of partial neutralization on the purification of divalent impurity metals from an $\mathrm{AgCl}$ solution was investigated by determining breakthrough curves. Details of the procedure are given in Table 2. Metal analyses of aqueous samples from the column effluent for $\mathrm{Ca}, \mathrm{Mg}, \mathrm{Pb}$ and $\mathrm{Zn}$ were carried out from $10 \% \mathrm{HNO}_{3}$ media and for $\mathrm{Ag}$ from 2 $\mathrm{M} \mathrm{NaCl}+2 \mathrm{M} \mathrm{HCl}$ media using inductively coupled plasma atomic emission spectroscopy (ICP-AES, device: IRIS Intrepid Duo, Thermo Electron Corporation).

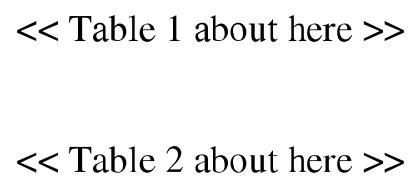

3. Results and discussion

\subsection{Titration curves}

According to literature, an aminomethylphosphonium group has three $\mathrm{p} K_{\mathrm{a}}$ values: 1.45 and 5.4 for the phosphonium group, and 11.0 for the amino group [12]. As can be observed in Fig. 2, Lewatit TP-260 was found to have a remarkably flat titration curve, which is typical for weak acid and weak base resins [2,10]. Such flatness is mostly because the three different groups have different $\mathrm{H}^{+}$binding behavior but also partly because of heterogeneity of the polymer. The individual $\mathrm{p} K_{\mathrm{a}}$ values for phosphonium groups cannot be distinguished from the experimental titration curve. Consequently, totally neutralizing the acidic phosphonium groups while leaving all of the amino groups protonated in the controlled partial neutralization experiments may be challenging.

The titration curves obtained with and without an electrolyte background differ remarkably. Generally, the resin is neutralized more easily in the presence of $\mathrm{NaCl}$, because $\mathrm{Na}^{+}$replaces some $\mathrm{H}^{+}$from the cation exchange group $[2,10]$. The curves in pure $\mathrm{H}_{2} \mathrm{O}$ and $0.5 \mathrm{M} \mathrm{NaCl}$ cross at around $\log c_{\mathrm{H}_{+}}=-6$ and at higher acidity the resin was protonated more easily in $0.5 \mathrm{M} \mathrm{NaCl}$ than in $\mathrm{H}_{2} \mathrm{O}$. Increasing the salt concentration from 0.5 to $4.5 \mathrm{M}$ also had a remarkable diminishing effect on the protonation.

Based on the titration curves, the $\mathrm{H}^{+}$capacity of phosphonium groups in Lewatit TP260 in every background electrolyte concentration used is around $2.3 \mathrm{mmol} / \mathrm{mL}$ resin, 
157 which corresponds to the value given by the manufacturer [11]. The titration curves in the

$158 \mathrm{NaCl}$ background are in correspondence with the results of Vaaramaa and Lehto [13] and 159 without background $\mathrm{NaCl}$ the curve corresponds to the $\mathrm{p} K_{\mathrm{a}} 11.0$ for the amino group (in $1600.1 \mathrm{M} \mathrm{KNO}_{3}$ ) given by Nesterenko et al. [8]. The protonation behavior of the amine group 161 is seen mostly in the negative side of the titration curves because the amine group is in 162 protonated form after the pretreatment, in which the last stage is a water wash. In water and $1630.5 \mathrm{M} \mathrm{NaCl}$ the amine group part of the curve is more abrupt than in $4.5 \mathrm{M} \mathrm{NaCl}$. 164 Consequently, it might be challenging to achieve the desired extent of neutralization in 165 controlled partial neutralization experiments. The $\mathrm{H}^{+}$capacity of the amine group in every background was $\sim 1.1 \mathrm{mmol} / \mathrm{mL}$, which is approximately half the $\mathrm{H}^{+}$capacity in the phosphonium groups, as would be expected based on the chemical structure of the functional group (Fig. 1).

\subsection{Neutralization profiles}

The ideal level of neutralization of the resin would be $67 \%$, meaning that the two protons in each phosphonium group would be completely neutralized while each amino group would still be in protonated form. In such a state, the neutralized phosphonium parts of the functional groups will prevent loss of metal uptake capacity caused by competition of protons with metals. The protonated amine parts in turn, will prevent potential precipitation problems caused by $\mathrm{pH}$ increase that occurs if protons are taken up by the amine part.

Different types of neutralization agents in a concentrated $\mathrm{NaCl}$ background were tested for controlled partial neutralization: neutral salt solution $(\mathrm{NaCl})$, dilute and concentrated bases $(\mathrm{NaOH})$, phosphate buffer $\left(\mathrm{Na}_{2} \mathrm{HPO}_{4}\right)$ and salts of monoprotic and triprotic weak organic acids. The total concentration of $\mathrm{Na}^{+}$in the neutralization solution was between 4.5 $\mathrm{M}$ and 4.8 $\mathrm{M}$ in all cases. As shown in Fig. 3, the best neutralization agents are the buffer type solutions, such as $0.5 \mathrm{M} \mathrm{NaAc}$ and $0.2 \mathrm{M} \mathrm{Na}_{2} \mathrm{HPO}_{4}$. This is due to the fact that they have the ability to capture and bind $\mathrm{H}^{+}$from the phosphate groups of the resin in the neutral or slightly acidic $\mathrm{pH}$ range. 
As observed in Fig. 3, there is an undesired gradient in the extent of neutralization along the bed when these concentration levels of neutralization agents were used. The extents of neutralization obtained with $0.5 \mathrm{M} \mathrm{NaAc}$ and $0.2 \mathrm{M} \mathrm{Na}_{2} \mathrm{HPO}_{4}$ were $55 \%$ and $59 \%$ near the column inlet and $31 \%$ and $36 \%$ near the outlet.

According to the titration curve (Fig. 2), the desired extent of neutralization would eventually be achieved also with $4.5 \mathrm{M} \mathrm{NaCl}$ at neutral $\mathrm{pH}$ or with $0.001 \mathrm{M} \mathrm{NaOH}$ in absence of salt. However, the capability of neutral or slightly basic solutions to remove $\mathrm{H}^{+}$ from the phosphonium groups is so small that neutralization up to the desired extent would require excessive solution volumes and time. In these experiments, the extent of neutralization remained under $30 \%$ with $4.8 \mathrm{M} \mathrm{NaCl}$ and $0.001 \mathrm{M} \mathrm{NaOH}$ through the whole column.

Finally, it is observed in Fig. 3 that concentrated $\mathrm{NaOH}$ is too strong a neutralizing agent, converting also the amino group to unprotonated form. This is not acceptable because the $\mathrm{pH}$ of the metal solution to be purified would increase significantly as the amino group captures $\mathrm{H}^{+}$from the liquid phase.

$\mathrm{NaAc}$ was found to be a more effective neutralizing agent than $\mathrm{NaFo}$, leading to 15 25 percentage units higher extent of neutralization along the resin bed (Fig. 4). The

208 difference between the inlet and outlet was about 20 percentage units with both salts. This 209 result is readily explained by the acid strength of the substances. For HAc and HFo, the $210 \mathrm{p} K_{\mathrm{a}}$ values are respectively $4.48\left(45^{\circ} \mathrm{C}, 0.7 \mathrm{M} \mathrm{NaCl}\right)$ and $3.78\left(50^{\circ} \mathrm{C}, \mathrm{KCl}\right)$ [14]. The top of 211 the bed meets fresh neutralization solution that captures $\mathrm{H}^{+}$from the resin. The higher the $212 \mathrm{p} K_{\mathrm{a}}$ of the acid, the more $\mathrm{H}^{+}$it can bind before the system reaches a local equilibrium. 213 When the solution reaches the bottom of the bed, the weak acids are already carrying a 214 large amount of $\mathrm{H}^{+}$and the $\mathrm{pH}$ of the solution is much lower than near the inlet. The 215 degree of neutralization therefore increases more slowly near the outlet of the column than 216 at the inlet. 
$217 \mathrm{Na}_{3} \mathrm{Ci}$ gave similar neutralization results as $\mathrm{NaAc}$, although it gave a higher extent of

218 neutralization near the column outlet and thus a smoother neutralization profile (Fig. 4).

$219 \mathrm{H}_{3} \mathrm{Ci}$ is a triprotic acid with $\mathrm{p} K_{\mathrm{a}}$ values $3.05,4.40$ and $5.52\left(35^{\circ} \mathrm{C}, \mathrm{KNO}_{3}\right)$ [15]. The third

220 hydroxyl in citrate is a stronger proton acceptor than the acetate anion, the second is rather

221 similar to acetate, and the third one is a weaker proton acceptor than acetate. All of these

222 are in the range that they can be effective in a partial neutralization process, so it is

223 reasonable that citrate has a higher capacity per mole to take $\mathrm{H}^{+}$than the salts of

224 monoprotic carboxylic acids. However, it can be concluded from the neutralization profiles

225 in Fig. 4 that the higher proton acceptor capacity and the one unit higher third $\mathrm{p} K_{\mathrm{a}}$ value do

226 not yield a significantly higher extent of neutralization in the inlet side of the column. This

227 finding implies that mass transfer phenomena also had some effect at these experimental 228 conditions

The effect of the amount of NaAc on neutralization is displayed in Fig. 5, which shows axial profiles obtained with different acetate concentrations and with different neutralization times. Increasing the acetate concentration from $0.2 \mathrm{M}$ to $2.0 \mathrm{M}$ resulted in a 15 percentage units higher extent of neutralization at the column inlet and 35 percentage units higher extent of neutralization at the outlet. The gradient in the bed was thus shallower with the more concentrated solution. As expected, increasing the length of the neutralization cycle had a positive effect on the extent of neutralization. A significantly higher level was reached when $0.2 \mathrm{M} \mathrm{NaAc}$ was fed into the column for 20 minutes instead

240 of 10 minutes. The increase was highest near the column outlet (17 percentage units) than near the inlet (8 percentage units), meaning that the profile was also shallower. With the

242 longer neutralization cycle the extent of neutralization varied between $58 \%$ (inlet) and 39 $243 \%$ (outlet).

244 On the other hand, nearly the same extent of neutralization was achieved with $20 \mathrm{~min}$ neutralization time and $0.2 \mathrm{M} \mathrm{NaAc}$ (i.e., in total $0.04 \mathrm{~mol}$ of $\mathrm{NaAc}$ ) as with 10 min cycle and $0.5 \mathrm{M} \mathrm{NaAc}$ (i.e., in total $0.05 \mathrm{~mol}$ of $\mathrm{NaAc}$ ). The main difference in the profiles was 
residence time. This finding indicates that the role of mass transfer effects cannot be neglected under these experimental conditions. From the practical process design point of view, it would be preferable to use as concentrated a solution as possible to shorten the time required for achieving certain extent of neutralization, which is in accordance with the theory of ion exchange column dynamics that predicts shorter regeneration cycles with highly concentrated regeneration solutions [2]. It should be noted that an almost uniform neutralization profile with near optimal extent of neutralization (64-70\%) was achieved with 2.0 M NaAc and a 20 min regeneration step.

$<<$ Figure 5 about here $>>$

\subsection{Purification of a multimetal solution}

The influence of controlled partial neutralization on the adsorption of metals to an aminomethylphosphonic acid resin is shown in Fig. 6. For example, in the case of neutralization with 2.0 M NaAc (Run 6 in Table 2), the breakthroughs of $\mathrm{Pb}, \mathrm{Mg}, \mathrm{Ca}$, and $\mathrm{Zn}$ occurred at 6.0, 6.5, 8.0, and $15.2 \mathrm{BV}$, respectively. Without neutralization, they occurred at $0.8,2.6,3.8$ and $3.2 \mathrm{BV}$, respectively. It can further be observed in Fig. 6 that the breakthrough order of the metals was not affected except for Zn, which broke through before $\mathrm{Ca}$ without neutralization and after all other metals with neutralization. As expected, the target product, $\mathrm{AgCl}$, was not affected by neutralization because the resin has much higher affinity towards $\mathrm{H}^{+}$than $\mathrm{Ag}^{+}$.

When comparing different neutralization agents by considering the breakthrough curves of the four divalent metals (Fig. 7), NaFo was found to show the worst performance (except for the experiment without neutralization). The differences between the other neutralization agents were relatively small. $2.0 \mathrm{M} \mathrm{NaAc}$ and $0.5 \mathrm{M} \mathrm{Na}_{3} \mathrm{Ci}$ resulted in a slightly higher dynamic uptake capacity for all the metals than $0.5 \mathrm{M} \mathrm{NaAc}$ or $0.2 \mathrm{M}$ $\mathrm{Na}_{2} \mathrm{HPO}_{4}$. It is noteworthy that the adsorbed amount of all metals except $\mathrm{Ca}$ increased with increasing extent of neutralization. This is particularly clear from the breakthrough curve of $\mathrm{Pb}$, where the displacement effect is much more pronounced when higher extent of neutralization was reached. 
The effect of controlled partial neutralization on metal sorption can also be explained by considering the $\mathrm{pH}$ values at the column outlet (see Fig. 7). The $\mathrm{pH}$ of the column effluent at the beginning of the metals loading step gives an indication of the extent of neutralization in the column. A low pH stems from displacement of $\mathrm{H}^{+}$by $\mathrm{Na}^{+}$during the washing step (with $4.8 \mathrm{M} \mathrm{NaCl}$ at $\mathrm{pH} 6.5$ ) that follows the neutralization step (see Table 2). In all cases, the $\mathrm{pH}$ changed fairly little for a duration of several bed volumes at the beginning of the loading step, which means that there was no steep $\mathrm{pH}$ gradient in the bed after the washing step. Without neutralization (Run 1 in Table 2), the $\mathrm{pH}$ dropped below unity as the metals were taken up by the resin. The $\mathrm{pH}$ rose slowly towards a value of 2 by the end of the experiment (approximately $35 \mathrm{BV}$ feed). Considering the titration curve displayed in Fig. 2, it is obvious that the resin is nearly completely in $\mathrm{H}^{+}$form at such low $\mathrm{pH}$. With 2.0 M NaAc neutralization (Run 6), the outlet $\mathrm{pH}$ was approximately 6 in the beginning of the feeding step and started to decrease after approximately $8 \mathrm{BV}$ of feed, remaining just below 4 at the end of the run (approximately $50 \mathrm{BV}$ of feed).

To describe the comparison of the neutralization agents numerically, the 5\% breakthrough points $\left(c / c^{0}=0.05\right)$ for all the metals and for each neutralization agent are given in Table 3. It should first be noted that $\mathrm{Ag}$ was practically not adsorbed at all. The breakthrough sequence was the same in every experiment where neutralization was applied: $\mathrm{Zn}>\mathrm{Ca}>\mathrm{Mg}>\mathrm{Pb}>\mathrm{Ag}$. From Table 3 it can also be seen that when neutralization was not applied, $\mathrm{Pb}$ breaks through almost immediately (at $1.4 \mathrm{BV}$ ) and thus only a very small amount of the $\mathrm{AgCl}$ solution could be purified. If the required product quality is defined such that none of the impurity metals can exceed $5 \%$ of its initial concentration at column outlet, the productivity of the separation process proportional to the difference between the breakthrough volumes of $\mathrm{Pb}$ and $\mathrm{Ag}$ (the latter is always approximately $1 \mathrm{BV})$. $2.0 \mathrm{M} \mathrm{NaAc}$ neutralization was found to be most effective $(\mathrm{Pb}$ breakthrough at $6.5 \mathrm{BV}$ ), while productivities obtained with $0.5 \mathrm{M} \mathrm{Na}_{3} \mathrm{Ci}, 0.2 \mathrm{M} \mathrm{NaHPO}_{4}$, $0.5 \mathrm{M} \mathrm{NaAc}, 0.5 \mathrm{M} \mathrm{NaFo}$ and pure $\mathrm{NaCl}$ were $84 \%, 84 \%, 69 \%, 36 \%$ and $7 \%$ of that value. (1) $\ll$ Figure 6 about here $\gg>$ $<<$ Figure 7 about here $>>$ 


\section{Conclusions}

313

The aim of this study was to find suitable reagents and conditions to partially neutralize an aminomethylphosphonium functional resin (Lewatit TP-260). More precisely, the goal was to leave the amine group protonated while completely neutralizing the phosphonium group, thus preventing undesired $\mathrm{pH}$ changes while permitting adsorption of metals from neutral solutions. A concentrated strong base $(\mathrm{NaOH})$ by itself was found to be too strong a neutralizing agent, converting the nitrogen group into free base form. $4.8 \mathrm{M}$ $\mathrm{NaCl}$ at neutral $\mathrm{pH}$ or $0.001 \mathrm{M} \mathrm{NaOH}$ was found to result in too low extent of neutralization within a reasonable time. However, both sodium salts of organic acids and a phosphate buffer were found to be suitable neutralizing agents.

The length of the neutralization step and the concentration of the neutralizing agent were found to be more important factors in controlled partial neutralization than the choice of organic acid salt. The most favourable neutralization profile was achieved with $7.5 \mathrm{BV}$ of $2.0 \mathrm{M} \mathrm{NaAc}$, which yielded $63-70 \%$ extent of neutralizationalong the column, while the desired extent is $67 \%$.

Purification of an $\mathrm{Ag}-\mathrm{NaCl}$ solution from $\mathrm{Ca}, \mathrm{Mg}, \mathrm{Pb}$ and $\mathrm{Zn}$ in a single column operation was used as a model system. Practically no separation was achieved with the resin in acid form resin since $\mathrm{Pb}$ broke through almost immediately. By employing the controlled partial neutralization procedure with $2.0 \mathrm{M} \mathrm{NaAc}$, up to $5.5 \mathrm{BV}$ of the $\mathrm{Ag}-\mathrm{NaCl}$ solution could be purified before regeneration of the resin was required.

The main benefit of the controlled partial neutralization method over the use of buffered feed solutions is that no additional chemicals are introduced into the purified solution.

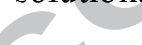

\section{Acknowledgments}

Authors wish to acknowledge Ms. Anne Hyrkkänen for experimental assistance. The Finnish Funding Agency for Technology and Innovation (ELEMET program), OMG Kokkola Chemicals Oy, Outotec Finland Oyj, Norilsk Nickel Harjavalta Oy, Talvivaara Mining Company, and Academy of Finland (Grant No. 252688) are acknowledged for financial support. 
[1] J. Wyethe, M. Kotze, B. Van Hege, R. Bell, The Use of Selective Ion Exchange for the Recovery of Base Metals from Effluent Streams, in: South African Institute of Mining and Metallurgy, Zambia, 2005.

[2] F. Helfferich, Ion Exchange, Dover Publications, Inc., 1995.

[3] B. Kiehling, W. Hoell, Partially desalinating water with ion exchanger materials which are subsequently regenerated, IL66421A, 1985.

[4] R. Kunin, B. Vassiliou, Regeneration of carboxylic cation-exchange resins with carbon dioxide, Ind. Eng. Chem. Prod. Res. Dev. 2 (1963) 1-3.

[5] A.L. Larsen, Regenerating resins of deionization systems, US3691109A, 1972.

[6] J.E. Greenleaf, A.K. Sengupta, Environmentally benign hardness removal using ionexchange fibers and snowmelt, Environ Sci Technol. 40 (2006) 370-376.

[7] J.P. Bayard, G. Bayard, Water free of heavy metals for medical use and ion exchange resin used in its preparation, FR2506286A1, 1982.

[8] A.W. Trochimczuk, M. Streat, Novel chelating resins with aminothiophosphonate ligands, Reactive and Functional Polymers 40 (1999) 205-213.

[9] A.W. Trochimczuk, Chelating resins with $\mathrm{N}$-substituted diamides of malonic acid as ligands, European Polymer Journal 34 (1998) 1657-1662.

[10] K. Dorfner, Ion exchangers, Walter de Gruyter, Berlin, 1991.

[11] Lewatit TP-260 Product information, (2010).

[12] P.N. Nesterenko, M.J. Shaw, S.J. Hill, P. Jones, Aminophosphonate-Functionalized Silica: A Versatile Chromatographic Stationary Phase for High-Performance Chelation Ion Chromatography, Microchemical Journal 62 (1999) 58-69.

[13] K. Vaaramaa, J. Lehto, H+Na+ exchange in an aminophosphonate-chelating resin, Reactive and Functional Polymers 33 (1997) 19-24.

[14] Harned, Embree, Journal of the American Chemical Society 56 (1934) 1042.

[15] L.A. Kochergina, V.P. Vasil'ev, D.V. Krutov, O.N. Krutova, The influence of temperature on the heat effects of acid-base interaction in aqueous solutions of citric acid, Russian Journal of Physical Chemistry 82 (2008) 565 - 570. 


\section{List of Figure Captions}

Figure 1. Chemical structure of the aminomethylphosphonic acid functional group of Lewatit TP-260.

Figure 2. Titration curves of aminomethylphosphonium functional Lewatit TP-260 resin in $\mathrm{NaCl}$ solutions of different concentrations.

Figure 3. Controlled partial neutralization profiles of aminomethylphosphonium functional resin (Lewatit TP-260). Comparison of different type neutralization agents.

Figure 4. Controlled partial neutralization profiles of aminomethylphosphonium functional resin (Lewatit TP-260). Comparison of different organic acid salts.

Figure 5. Controlled partial neutralization profiles of aminomethylphosphonium functional resin (Lewatit TP-260). Influence of NaAc concentration and cycle length.

Figure 6. Single column adsorption of divalent metals to aminomethylphosphonium functional resin (Lewatit TP-260) from an Ag bearing solution. Breakthrough curves without (left) and with (right) controlled partial neutralization $(2.0 \mathrm{M}$ $\mathrm{NaAc}+2.8 \mathrm{M} \mathrm{NaCl})$.

Figure 7. Single column adsorption of divalent metals to aminomethylphosphonium functional resin (Lewatit TP-260) from Ag bearing solution. Breakthrough curves for individual metals and $\mathrm{pH}$ curves (from multimetal feed) with different neutralization agents. 


\section{List of Tables}

410

411

Table 1. Experimental procedure for studying the neutralization profiles in the resin bed after controlled partial neutralization.

413

414

415

Table 2. Experimental procedure for investigating metal separation with partially neutralized resin by breakthrough experiments.

416 Table 3. Single column adsorption of divalent metals to aminomethylphosphonium 417 functional resin (Lewatit TP-260) from Ag bearing solution. 5\% breakthrough volume for each metal with different neutralization agents. 


\begin{tabular}{|c|c|c|c|}
\hline Step description & Feed solution & Duration, min & $\begin{array}{l}\text { Flow rate, } \\
\mathrm{mL} / \mathrm{min}\end{array}$ \\
\hline Conversion to acid form & $2.0 \mathrm{M} \mathrm{HCl}+2.0 \mathrm{M} \mathrm{NaCl}$ & 30 & 6 \\
\hline Washing & $4.8 \mathrm{M} \mathrm{NaCl}, \mathrm{pH} 6.5$ & 5 & 10 \\
\hline \multicolumn{4}{|l|}{ Partial neutralization } \\
\hline Run 1 & $4.8 \mathrm{M} \mathrm{NaCl}, \mathrm{pH} 6.5$ & 10 & 5 \\
\hline Run 2 & $0.001 \mathrm{M} \mathrm{NaOH}+4.8 \mathrm{M} \mathrm{NaCl}, \mathrm{pH} 9.2$ & 10 & 5 \\
\hline Run 3 & $1.5 \mathrm{M} \mathrm{NaOH}+3.0 \mathrm{M} \mathrm{NaCl}$ & 10 & 5 \\
\hline Run 4 & $0.2 \mathrm{M} \mathrm{NaAc}+4.5 \mathrm{M} \mathrm{NaCl}, \mathrm{pH} 7.1$ & 10 & 10 \\
\hline Run 5 & $0.2 \mathrm{M} \mathrm{NaFo}+4.5 \mathrm{M} \mathrm{NaCl}, \mathrm{pH} 8.8$ & 10 & 10 \\
\hline Run 6 & $0.2 \mathrm{M} \mathrm{Na}_{2} \mathrm{HPO}_{4}+4.5 \mathrm{M} \mathrm{NaCl}, \mathrm{pH} 7.9$ & 10 & 10 \\
\hline Run 7 & $0.5 \mathrm{M} \mathrm{NaAc}+4.5 \mathrm{M} \mathrm{NaCl}, \mathrm{pH} 6.1$ & 10 & 10 \\
\hline Run 8 & $0.5 \mathrm{M} \mathrm{NaFo}+4.5 \mathrm{M} \mathrm{NaCl}, \mathrm{pH} 9.0$ & 10 & 10 \\
\hline Run 9 & $0.5 \mathrm{M} \mathrm{Na}_{3} \mathrm{Cl}+4.5 \mathrm{M} \mathrm{NaCl}, \mathrm{pH} 8.7$ & 10 & 10 \\
\hline Run 10 & 2.0 M NaAc + 2.8 M NaCl, $\mathrm{pH} 9.0$ & 10 & 10 \\
\hline Run 11 & $0.2 \mathrm{M} \mathrm{NaAc}+4.5 \mathrm{M} \mathrm{NaCl}, \mathrm{pH} 8.9$ & 20 & 10 \\
\hline Run 12 & $0.2 \mathrm{M} \mathrm{NaFo}+4.5 \mathrm{M} \mathrm{NaCl}, \mathrm{pH} 8.6$ & 20 & 10 \\
\hline Run 13 & 2.0 M NaAc + 4.5 M NaCl, pH 9.0 & 20 & 10 \\
\hline Washing & $4.8 \mathrm{M} \mathrm{NaCl}$ & 5 & 10 \\
\hline Rinse & Deionized water & 15 & 4 \\
\hline
\end{tabular}




\begin{tabular}{|c|c|c|c|}
\hline Step description & Feed solution & $\begin{array}{l}\text { Duration, } \\
\mathrm{mL} / \mathrm{min}\end{array}$ & $\begin{array}{l}\text { Flow rate, } \\
\mathrm{mL} / \mathrm{min}\end{array}$ \\
\hline Conversion to acid form & $2.0 \mathrm{M} \mathrm{HCl}+2.0 \mathrm{M} \mathrm{NaCl}$ & 30 & 6 \\
\hline Washing & $4.8 \mathrm{M} \mathrm{NaCl}, \mathrm{pH} 6.5$ & 5 & 10 \\
\hline \multicolumn{4}{|l|}{ Partial neutralization } \\
\hline Run 1 & $4.8 \mathrm{M} \mathrm{NaCl}, \mathrm{pH} 6.5$ & 10 & \\
\hline Run 2 & $0.2 \mathrm{M} \mathrm{Na}_{2} \mathrm{HPO}_{4}+4.5 \mathrm{M} \mathrm{NaCl}, \mathrm{pH} 8.7$ & 10 & \\
\hline Run 3 & $0.5 \mathrm{M} \mathrm{NaAc}+4.5 \mathrm{M} \mathrm{NaCl}, \mathrm{pH} 8.4$ & 10 & 10 \\
\hline Run 4 & $0.5 \mathrm{M} \mathrm{NaFo}+4.5 \mathrm{M} \mathrm{NaCl}, \mathrm{pH} 8.7$ & 10 & 10 \\
\hline Run 5 & $0.5 \mathrm{M} \mathrm{Na}_{3} \mathrm{Ci}+4.5 \mathrm{M} \mathrm{NaCl}, \mathrm{pH} 8.9$ & 1 & 10 \\
\hline Run 6 & $2.0 \mathrm{M} \mathrm{NaAc}+2.8 \mathrm{M} \mathrm{NaCl}, \mathrm{pH} 8.4$ & 10 & 10 \\
\hline Washing & $4.8 \mathrm{M} \mathrm{NaCl}, \mathrm{pH} 6.5$ & 5 & 10 \\
\hline Loading & $\begin{array}{l}\text { Metals (Ag, Ca, Mg, Pb, Zn) } 537-887 \text { mg/L } \\
4.5 \mathrm{M} \mathrm{NaCl}, \mathrm{pH} 6.26-6.35\end{array}$ & ca. $100 \mathrm{BV}$ & 4 \\
\hline Elution & $2.0 \mathrm{M} \mathrm{HCl}+2.0 \mathrm{M} \mathrm{NaCl}$ & 25 & 6 \\
\hline Rinse & Deionized water & 5 & 10 \\
\hline
\end{tabular}




\begin{tabular}{|c|c|c|c|c|c|c|}
\hline \multirow[b]{2}{*}{ Metal } & \multicolumn{6}{|c|}{$5 \%$ Breakthrough, BV } \\
\hline & $4.8 \mathrm{M} \mathrm{NaCl}$ & $0.5 \mathrm{M}$ NaFo & $0.5 \mathrm{M} \mathrm{NaAc}$ & 2.0 $\mathrm{M} \mathrm{NaAc}$ & $0.5 \mathrm{M} \mathrm{Na}_{3} \mathrm{Ci}$ & $0.2 \mathrm{M} \mathrm{Na}_{2} \mathrm{HPO}_{4}$ \\
\hline $\mathrm{Ag}$ & 1.1 & 1.1 & 1.1 & 1.0 & 1.1 & 1.1 \\
\hline $\mathrm{Ca}$ & 8.8 & 6.8 & 7.3 & 8.0 & 8.1 & 8.2 \\
\hline $\mathrm{Mg}$ & 2.6 & 5.6 & 6.7 & 8.0 & 6.8 & 7.6 \\
\hline $\mathrm{Pb}$ & 1.4 & 3.0 & 4.8 & 6.5 & 5.6 & 5.6 \\
\hline $\mathrm{Zn}$ & 3.2 & 11.3 & 15.7 & 19.5 & 17.6 & 16.2 \\
\hline
\end{tabular}


PS-DVB

$\mathrm{NH}$

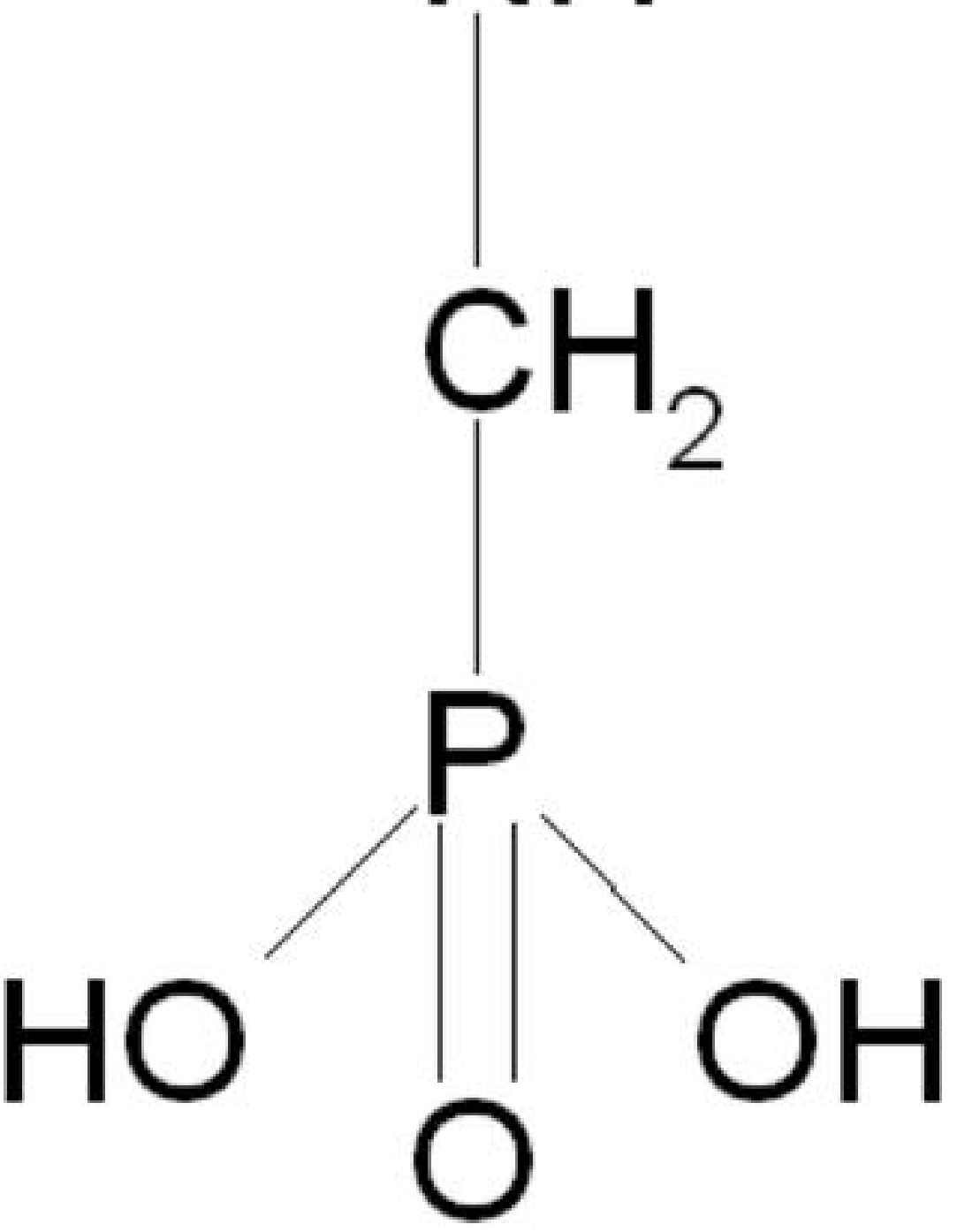


$\mathrm{q}_{\mathrm{H}^{+}}, \mathrm{mmol} / \mathrm{mL}$

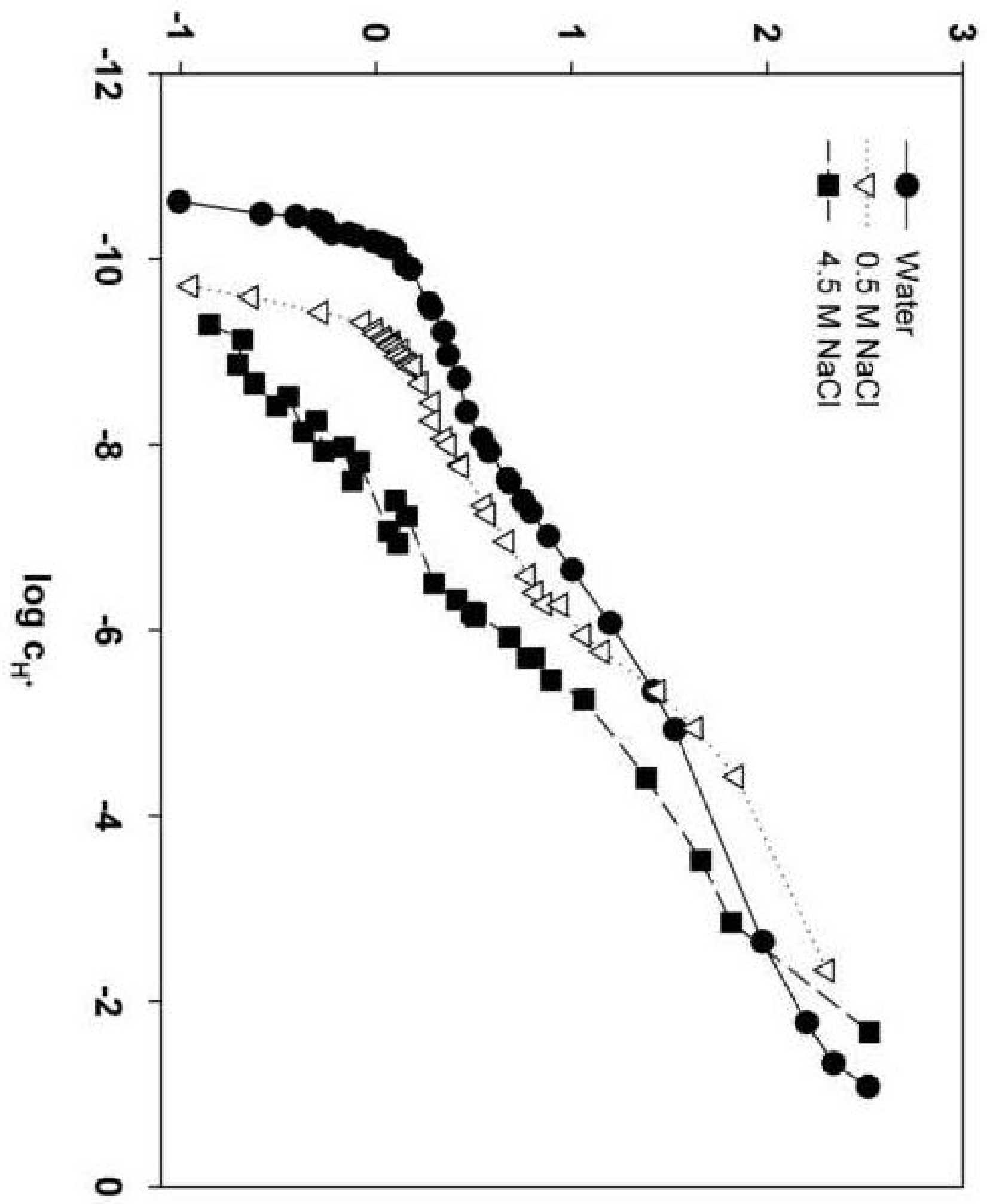


Extent of neutralization, \%

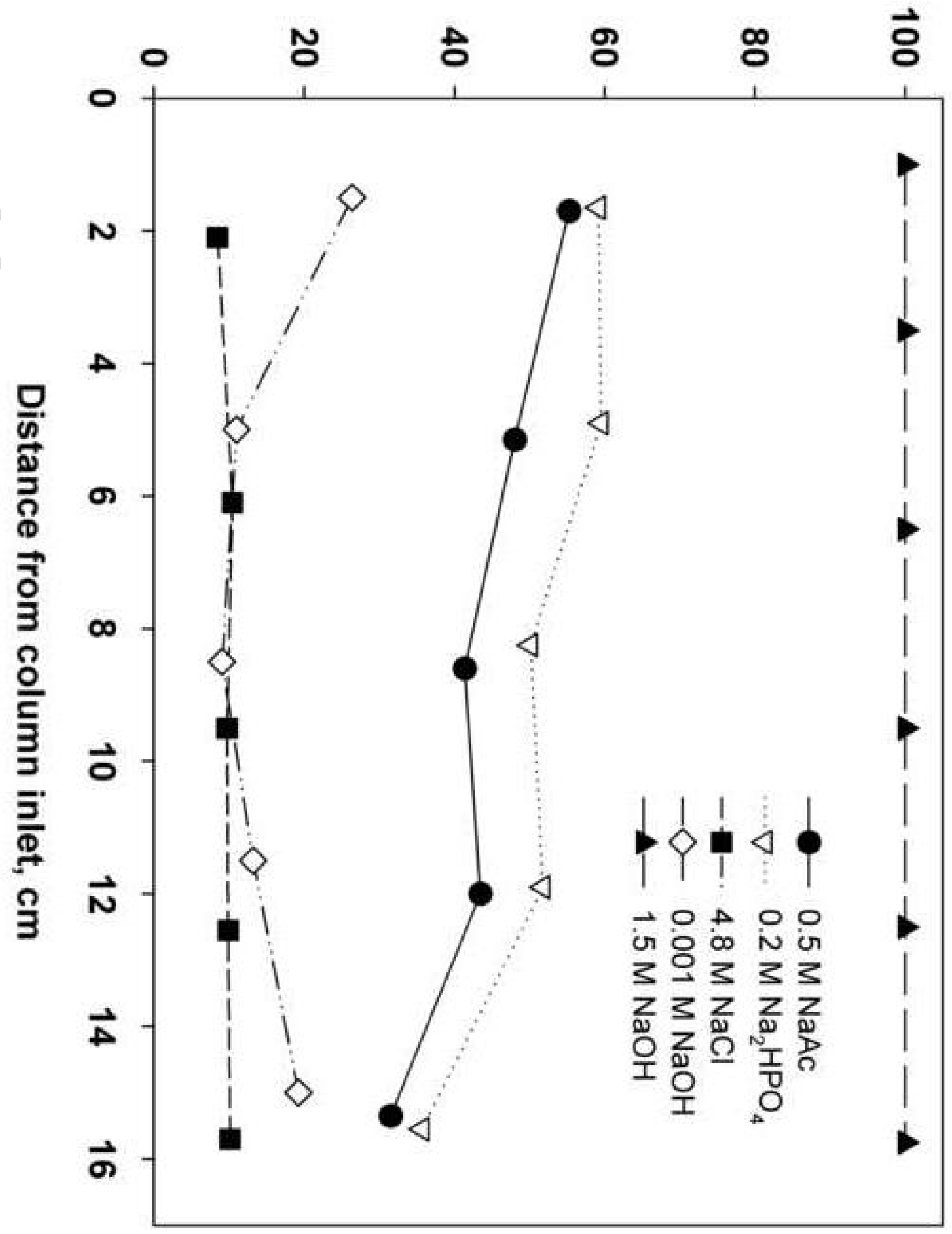


Extent of neutralization, \%

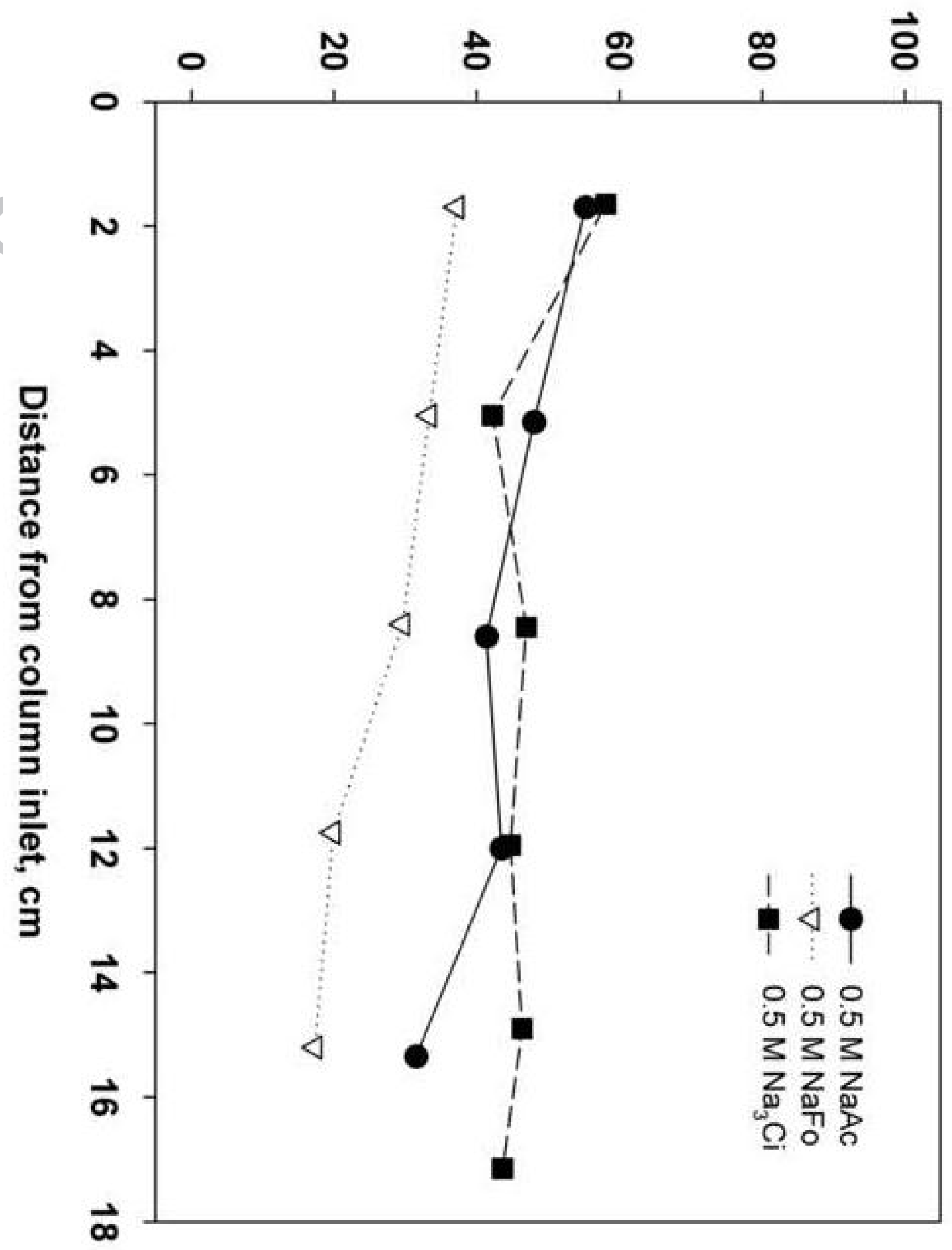


Extent of neutralization, \%

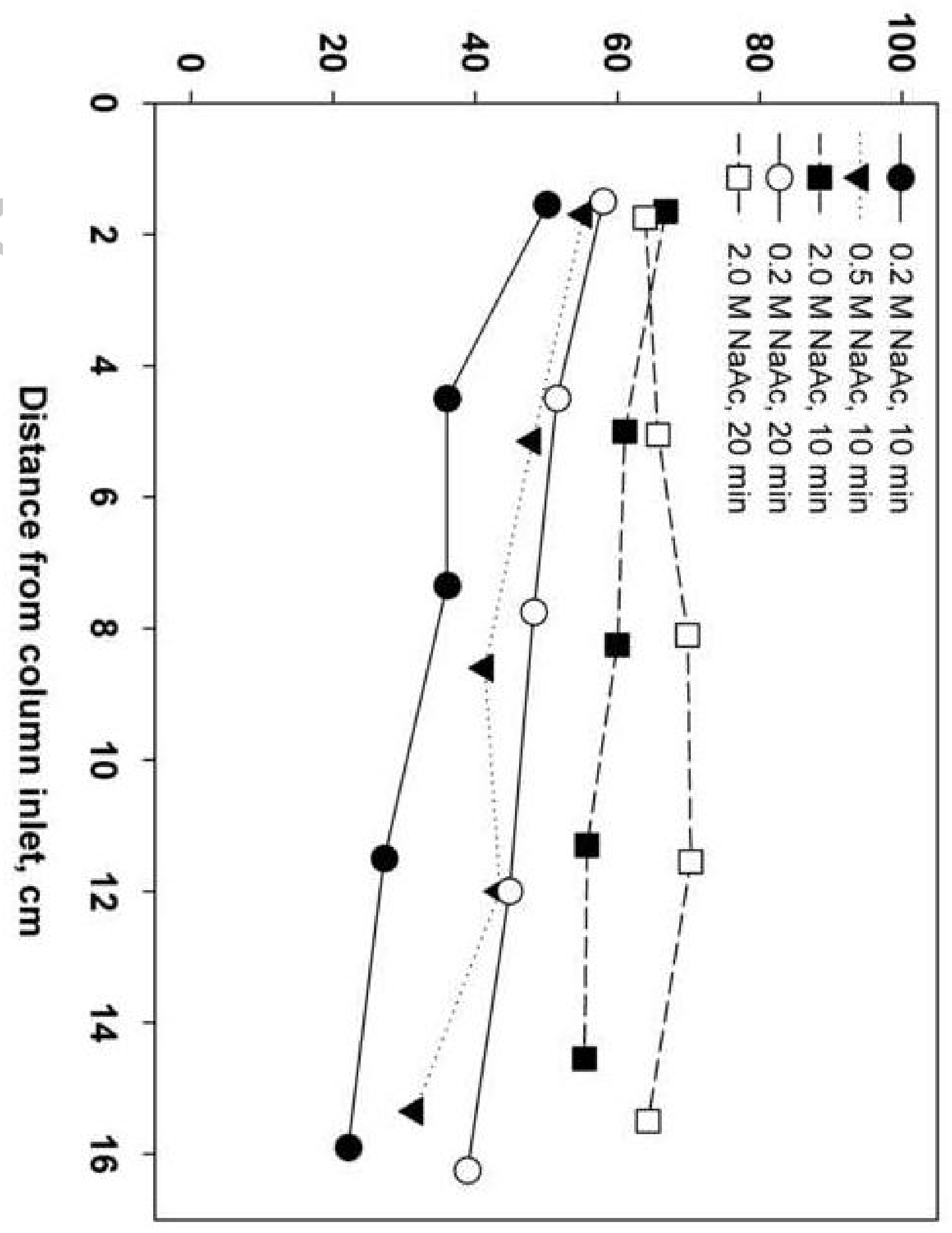



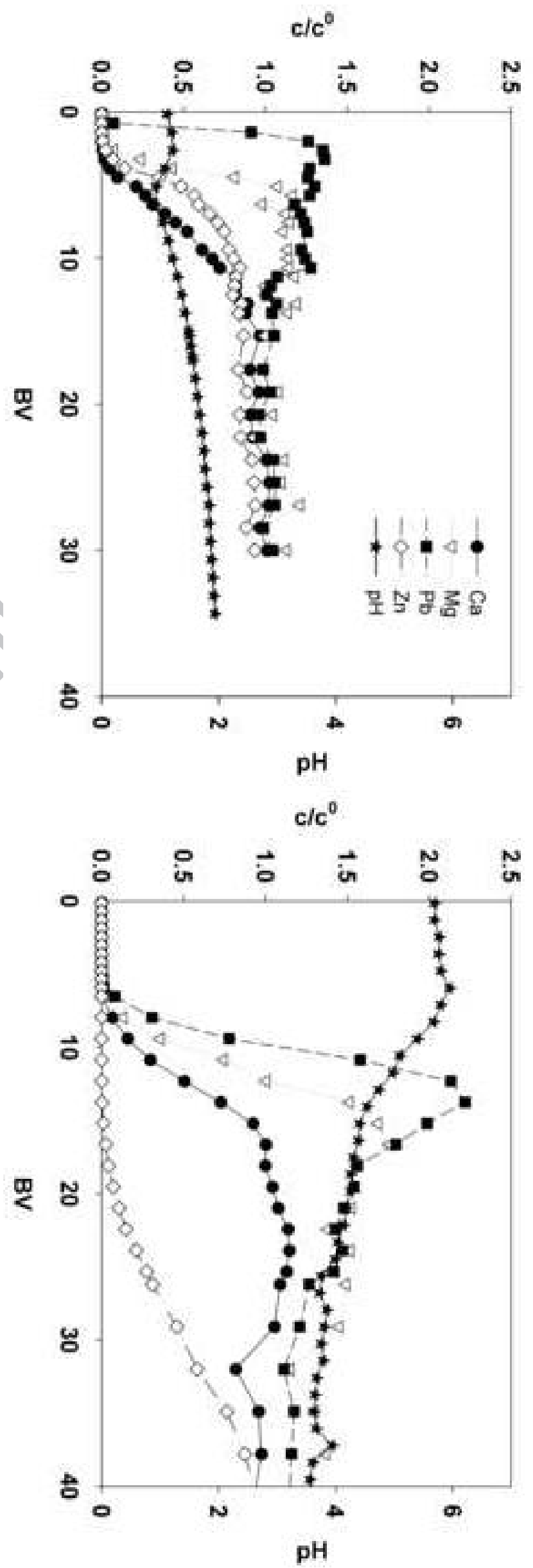

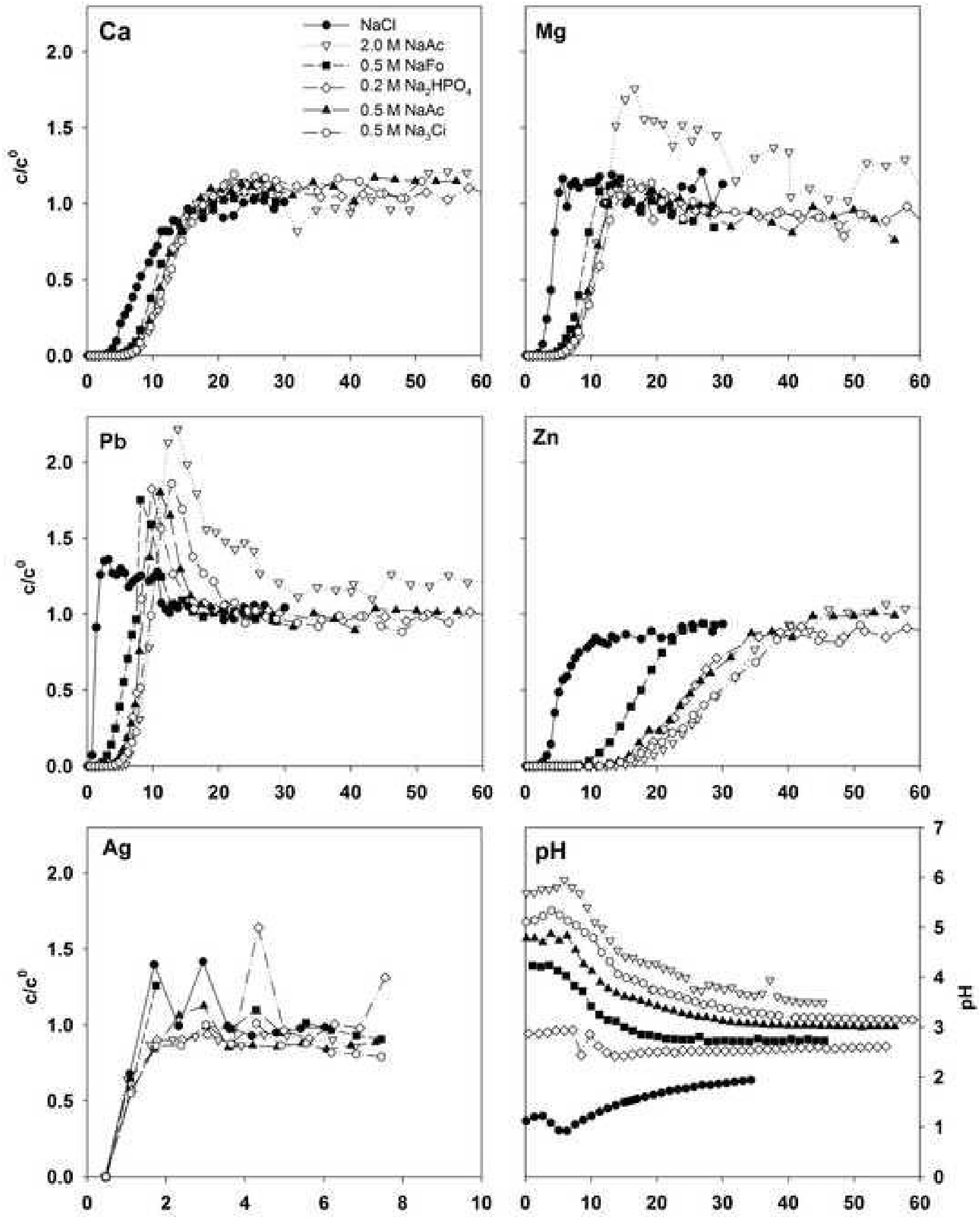

Feed volume, BV 